\title{
A Review of the Physiological and Immunological Functions of Biliary Epithelial Cells: Targets for Primary Biliary Cirrhosis, Primary Sclerosing Cholangitis and Drug-induced Ductopenias
}

\author{
CHIH-TE WU ${ }^{\mathrm{a}, *}$, PAUL A. DAVIS ${ }^{\mathrm{a}, *, \dagger}$, VELIMIR A. LUKETIC $^{\mathrm{b}}$ and M. ERIC GERSHWIN ${ }^{\mathrm{a}}$ \\ ${ }^{\mathrm{a}}$ Division of Rheumatology, Allergy and Clinical Immunology, University of California, Davis School of Medicine, Davis, CA 95616, USA; ${ }^{\mathrm{b}}$ Division of \\ Hepatology, Medical College of Virginia, Richmond, VA 23298, USA

\begin{abstract}
Our understanding of biliary epithelial cells (BEC) in physiobiology and immunology has steadily expanded. BEC transports IgA as well as IgM into bile, synthesizes and secretes various chemokines, cytokines, and expresses adhesion molecules involved in cell interaction and signal transduction. These then suggest a myriad of potential roles for BEC in defense from invading microorganisms as well as the pathogenesis of diverse immunologically driven diseases such as primary biliary cirrhosis (PBC), graft-versus-host disease, and primary sclerosing cholangitis (PSC). Despite the progress, there still remain many areas of BEC biology that require further investigation. Most importantly, it remains to be clarified that the extent to which the immunologic activities observed in BEC represent a BEC response to tissue injury or whether BEC themselves are the active participants in the pathogenesis of various cholestatic immunological diseases, including PBC and PSC.
\end{abstract}

Keywords: Biliary epithelial cells; Primary biliary cirrhosis; Primary sclerosing cholangitis; IgA

\section{INTRODUCTION}

The liver is composed of multiple cell types including two types of epithelia: hepatocytes, the major epithelial cells and intrahepatic biliary epithelial cells (BEC), which constitute $3-5 \%$ of the nuclear population of the liver (Tavoloni, 1987). BEC are typical epithelia, forming an extensive interconnecting network of intrahepatic and extrahepatic conduits which are heterogeneous with regard to diameter as well as their function. In humans, intrahepatic bile ducts range in size from $800 \mu \mathrm{m}$ hepatic ducts to $<15 \mu \mathrm{m}$ bile ductules. Physiologically, BEC participate in a variety of fundamental processes including formation of bile as well as the transport of IgA into bile. In recent years, it has become apparent that $\mathrm{BEC}$ represent critical targets for a diverse group of diseases, including primary biliary cirrhosis (PBC), primary sclerosing cholangitis (PSC) as well as drug-induced ductopenias. In this review, we will focus on the physiological as well as immunological functions of the BEC.

\section{BILE FORMATION AND ELECTROLYTE TRANSPORT}

Bile formation requires both hepatocytes and BEC as primary bile is extensively modified by BEC after its secretion by hepatocytes and prior to its delivery to the duodenum. BEC are responsible for approximately $30 \%$ of bile volume, a percentage that can be promptly increased to meet the changing physiological demands (Nathanson and Boyer, 1991). BEC secrete fluid, bicarbonate, chloride and immunoglobulin (Ig)A or reabsorb glucose, bile acids, amino acids, and electrolytes (Strazzabosco, 1997). The electrolyte transport function of the BEC is finely regulated by a complex system of intestinal hormones, neuropeptides, and neurotransmitters that promote either secretion or absorption. For example, secretin, which will be discussed in detail later, can increase the hydration and alkalinity of bile by stimulation of BEC secretion of chloride and bicarbonate.

\section{BEC SECRETORY PROCESSES}

Secretion into the bile is clearly a major function of BEC as they are a major determinant of alkalinity and hydration of bile and contribute significantly to the local bicarbonate needed for digestion. BEC bicarbonate secretion is driven by the apically located $\mathrm{Cl}^{-} / \mathrm{HCO}_{3}^{-}$exchanger, which is functionally coupled with the Cystic Fibrosis Transmembrane Conductance Regulator (CFTR), a cyclic AMP

\footnotetext{
*Contributed equally to manuscript.

Corresponding author. Address: Division of Rheumatology, Allergy and Clinical Immunology, TB 192, University of California at Davis School of Medicine, Davis, CA 95616, USA. Tel.: +1-530-752-2884. Fax: +1-530-754-6047. E-mail: padavis@ucdavis.edu
} 
(cAMP)-dependent $\mathrm{Cl}^{-}$channel. As noted earlier, secretin plays a major role in bicarbonate secretion as upon binding to its receptor, it increases intracellular cAMP levels, probably through a Gi-protein mediated induction of adenylate cyclase (Alvaro et al., 1997a). Once the intracellular cAMP increases, cAMP-dependent protein kinase A (PKA) is activated and phosphorylates thereby activating the regulatory domain of CFTR, a critical step before the stimulation of bicarbonate secretion (Alvaro et al., 1993; 1997b). This produces an open $\mathrm{Cl}^{-}$ conductance (Frizzel and Morris, 1994) and results in BEC mediated secretion of $\mathrm{Cl}^{-}$into the bile. The BEC driven rise in bile $\mathrm{Cl}^{-}$increases the $\mathrm{Cl}^{-} / \mathrm{HCO}_{3}^{-}$ exchanger activity, leading to increased $\mathrm{HCO}_{3}^{-}$secretion into the bile (in exchange of $\mathrm{Cl}^{-}$absorption into the BEC). Interestingly, the apical $\mathrm{Cl}^{-} / \mathrm{HCO}_{3}^{-}$exchanger lacks the ability to be stimulated by cAMP and therefore association with CFTR is required for cAMP-dependent $\mathrm{HCO}_{3}^{-}$ secretion. This $\mathrm{Cl}^{-} / \mathrm{HCO}_{3}^{-}$exchanger has been localized to the canalicular membrane of hepatocytes as well as the apical membrane of small and medium-sized bile ducts (Martinez-Anso et al., 1994) using monoclonal antibodies and to the medium and large bile ducts along with the secretin receptor and CFTR (Alpini et al., 1996) using functional studies.

Ductal bicarbonate secretion is also stimulated by bombesin and vasoactive intestinal peptide (VIP). Both of them, like secretin, enhance the activity of the $\mathrm{Cl}^{-} / \mathrm{HCO}_{3}^{-}$ exchanger after CFTR activation (Cho et al., 1997a,b). Conversely, ductal bicarbonate secretion is inhibited by somatostatin and gastrin. Somatostatin, after binding to SSTR2 subtype receptors, which are detected almost exclusively on large bile ducts, inhibits basal and secretinstimulated ductal bile flow. Somatostatin can also inhibit the secretin-induced increase of intracellular cAMP levels via a Gi-protein mediated inhibition of adenylate cyclase activity (Tietz et al., 1995). Gastrin also inhibits secretininduced bicarbonate secretion by decreasing the secretininduced cAMP levels and the expression of secretin receptor in BEC (Glaser et al., 1997). In contrast to somatostatin, gastrin does not affect basal bile flow.

Neural pathways also modulate $\mathrm{HCO}_{3}^{-}$secretion as vagal (cholinergic) stimulation increases $\mathrm{HCO}_{3}^{-}$secretion after acetylcholine binding to $\mathrm{M}_{3}$ muscarinic receptors on the basolateral membrane of $\mathrm{BEC} . \mathrm{M}_{3}$ receptor activation increases intracellular $\mathrm{Ca}^{2+}$ which recruits calcineurin, a $\mathrm{Ca}^{2+}$ - and calmodulin-dependent serine/threonine protein phosphatase $2 \mathrm{~B}$, that in turn sensitizes specific adenylate cyclase isoforms to secretin and thereby doubles intracellular cAMP. This finally results in an almost maximal stimulation of the $\mathrm{Cl}^{-} / \mathrm{HCO}_{3}^{-}$exchanger (Alvaro et al., 1997c; Alvaro, 1999). This effect is blocked by $\mathrm{M}_{3}$ muscarinic receptor antagonists, intracellular $\mathrm{Ca}^{2+}$ chelators, as well as the calcineurin inhibitors, FK-506 and cyclosporin A (Alvaro et al., 1997c). The secretory processes of BEC are also regulated by ATP. ATP increases intracellular $\mathrm{Ca}^{2+}$, induces intracellular alkalinization (activation of $\mathrm{Na}^{+} / \mathrm{H}^{+}$exchanger) and, as a consequence, enhances the activity of the $\mathrm{Cl}^{-} / \mathrm{HCO}_{3}^{-}$ exchanger (Elsing et al., 1996; Fitz, 1997; Strazzabosco, 1997). The coordinated regulation of bicarbonate secretion by secretin (cAMP) and acetylcholine $\left(\mathrm{Ca}^{2+}\right)$ could serve as a means of amplifying the secretory response just when the bicarbonate requirement in the intestine is maximal, i.e. the parasympathetic predominant digestive phase.

A number of different ion channels and carriers, in addition to the $\mathrm{Cl}^{-} / \mathrm{HCO}_{3}^{-}$exchanger and $\mathrm{CFTR}$, have also been identified on BEC. On the basolateral membrane, there are the $\mathrm{Na}^{+} / \mathrm{H}^{+}$exchanger isoform 1 (NHE1), the $\mathrm{Na}^{+}$-dependent $\mathrm{Cl}^{-} / \mathrm{HCO}_{3}^{-}$exchanger, the $\mathrm{Na}^{+}-\mathrm{K}^{+}{ }_{-}$ ATPase, and the $\mathrm{Na}^{+} / \mathrm{K}^{+} / 2 \mathrm{Cl}^{-}$cotransporter. The $\mathrm{Na}^{+}$dependent $\mathrm{Cl}^{-} / \mathrm{HCO}_{3}^{-}$exchanger absorbs $\mathrm{HCO}_{3}^{-}$into the cell (Strazzabosco et al., 1997). The $\mathrm{Na}^{+}-\mathrm{K}^{+}-$ATPase maintains the $\mathrm{Na}^{+}$gradient and, together with $\mathrm{K}^{+}$channels, determines the membrane potential difference of BEC. The $\mathrm{Na}^{+} / \mathrm{K}^{+} / 2 \mathrm{Cl}^{-}$cotransporter actively absorbs $\mathrm{Cl}^{-}$ions into the cell and appears to be a major determinant of fluid secretion (Singh et al., 1996). On the luminal surface of BEC, a Ca ${ }^{++}$-activated $\mathrm{Cl}^{-}$channel is present which may be activated by luminal purinergic nucleotides (Strazzabosco et al., 2000). More recent work has demonstrated the expression of the apical isoforms of $\mathrm{Na}^{+} / \mathrm{H}^{+}$exchanger (NHE2) (Spirli et al., 1998), which enhance $\mathrm{Na}^{+}$ reabsorption. Figure 1 summarizes the different electrolyte transport mechanisms in BEC.

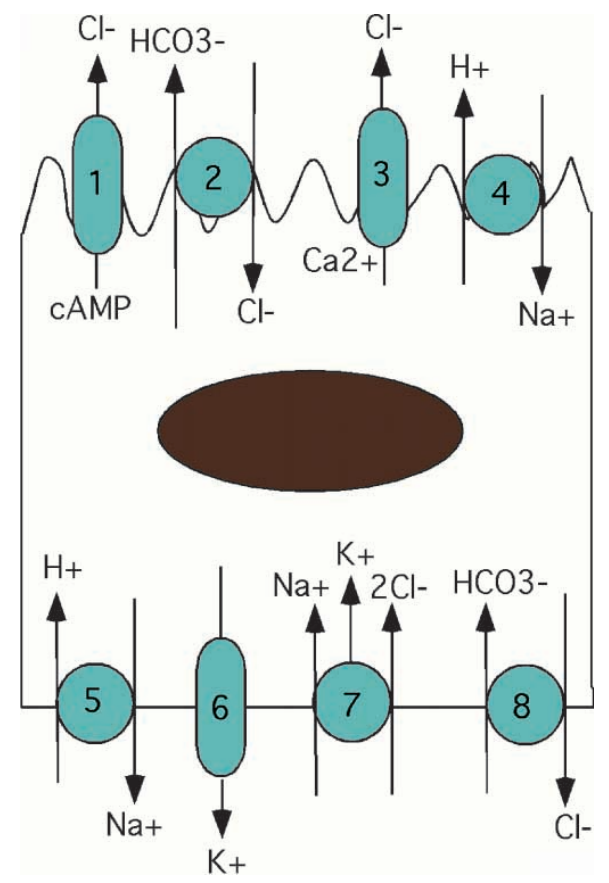

FIGURE 1 Mechanisms of electrolyte transport in biliary epithelial cells. At the apical membrane, the cystic fibrosis transmembrane conductance regulator (CFTR) (1) is couplewith the $\mathrm{Cl}^{-} / \mathrm{HCO}_{3}^{-}$ exchanger (2), which secretes $\mathrm{HCO}_{3}^{-}$in exchange of $\mathrm{Cl}^{-}$absorption. There is another $\mathrm{Ca}^{2+}$-dependent $\mathrm{Cl}^{-}$channel (3) as well as the $\mathrm{Na}^{+} / \mathrm{H}^{+}$ exchanger isoform 2 (NHE2) (4). On the basolateral side of the BEC, there is $\mathrm{Na}^{+} / \mathrm{H}^{+}$exchanger isoform 1 (NHE1) (5) and $\mathrm{K}^{+}$channel (6). Another type of $\mathrm{Cl}^{-} / \mathrm{HCO}_{3}^{-}$exchanger (7) and a $\mathrm{Na}^{+} / \mathrm{K}^{+} / 2 \mathrm{Cl}^{-}$ exchanger are also present. 


\section{ABSORPTIVE FUNCTIONS}

BEC are also capable of active reabsorption of glucose, bile acids, glutamate, conjugated bilirubin, sulfobromophthalein, and low molecular weight organic anions which further modify the final constituents of bile.

In isolated perfused rat livers, BEC absorbs both metabolizable hexose (D-glucose) and pentose (D-xylose) as well as nonmetabilizable hexoses ( $\alpha$-methylglucoside, 3-o-methylglucose, and L-glucose) (Lira et al., 1992). Because in sodium-free media, absorption of L-glucose and $\alpha$-methylglucoside gradually ceased while absorption of D-glucose and 3-o-methylglucose remained unchanged, there are at least two different sugar transport systems present.

Active transport processes for conjugated bile acids have recently been described using isolated rat cholangiocytes (Lazaridis et al., 1997). Conjugated bile acids were absorbed in a $\mathrm{Na}^{+}$-dependent fashion at the luminal BEC surface. Furthermore, immunohistochemistry also demonstrated the apical localization of the rat ileal $\mathrm{Na}^{+}-$ dependent bile acid transporter (ASBT). The meaning of the reabsorption remains to be clarified. However, intracellular bile acids are capable of modulating many important intracellular events including the level of secondary messengers $\left(\mathrm{Ca}^{2+}, \mathrm{cAMP}\right)$, vesicle trafficking, ion transport, growth and replication (Alvaro, 1999). Unlike conjugated bile acids, lipophilic, unconjugated bile acids, such as ursodeoxycholic acids, are passively reabsorbed. This provides the first essential step in the cholehepatic shunt model (Hofmann et al., 1997), which explains the phenomenon of bicarbonate rich hypercholeresis generated by these bile acids. The same phenomenon was also demonstrated for weakly acidic drugs, such as the anti-inflammatory sulindac (Hofmann et al., 1997). This has lead to speculation that cholehepatic recycling of the substances reabsorbed by BEC represents an additional removal step for unconjugated substances from the bile. As a major function of the liver is metabolism and conjugation of xenobiotics and drugs to be then secreted mainly as water-soluble metabolites into bile, substances that escape hepatic conjugation/metabolism might be excreted as hydrophobic (toxic) substances. However passive reabsorption by $\mathrm{BEC}$ and the continuous recycling likely are designed to ensure further conjugation/metabolism of these toxic metabolites. Final biliary excretion appears to occur only when this class of substances is rendered hydrophilic and non-toxic. In parallel, bile acids are also efficiently recycled under normal conditions after their release. Unconjugated, and to a lesser extent also conjugated, bile acids are absorbed by passive diffusion throughout the entire gut. However, an active transport mechanism for conjugated bile acids exists in the distal ileum. The reabsorbed bile acids enter the portal circulation and are taken up rapidly by hepatocytes, metabolized, and resecreted into the bile (enterohepatic circulation). Normally, the bile acid pool circulates approximately 5-10 times daily and intestinal reabsorption is $95 \%$ efficient, so fecal loss of bile acids is minimal. This loss is compensated by an equal daily synthesis of bile acids by the liver, thereby the size of the bile acid pool remains unchanged.

L-glutamate is released within the biliary tree from glutathione via the action of $\gamma$-glutamyl transferase (GGT). It has been shown that BEC possess the capacity for a sodium-dependent and sodium-independent transport system for L-glutamate. These transport systems are different from the hepatocellular system since the inhibition and kinetic properties are different (Eisenmann-Tappe et al., 1991). However, the localization of these transporters has not been identified yet, and therefore the physiological role of such a transport system remains unclear.

\section{IGA SECRETION}

IgA is the major protein in bile and is the major and characteristic immunoglobulin of the mucosal immune system (Lemaitre-Coelho et al., 1977). Two different pathways of $\operatorname{IgA}$ transport into bile are present. In humans, the IgA is synthesized locally in plasma cells along the biliary tree, bound to polymerized immunoglobulin receptor (pIgR) on the basolateral membrane of BEC, and transported, and secreted into the bile by BEC. In rats, the $\operatorname{IgA}$ is cleared from plasma by $\mathrm{pIgR}$ located on the sinusoidal surface of hepatocytes and delivered into bile. The major pathway for IgA transport into bile is via a receptor-binding interaction (Fig. 2). Studies in rats have demonstrated that IgA is transported by $\mathrm{pIgR}$, an extracellular receptor present in the sinusoidal membrane of hepatocytes. pIgR is synthesized as a transmembrane glycoprotein and is expressed in a polar fashion on the basolateral (or sinusoidal) surface of the cell, where it is available to bind IgA. pIgR is synthesized by the epithelial cells of all external-secreting organs (intestine, mammary gland, lung, lacrimal gland, endometrium, etc.) as well as by the hepatocytes and BEC (Takahashi et al., 1982; Delacroix et al., 1984; Daniels and Schmucker, 1987), as summarized in Table I.

$\operatorname{IgA}$ itself is synthesized in IgA-specific plasma cells as heavy chains (alpha) and light chains (kappa or lambda) which are assembled into monomeric IgA molecules (two heavy chains and two light chains). In the presence of the $\mathrm{J}$ chain addition peptide, monomeric units join via disulfide linkages to create dimers and other multimeric forms of IgA, which are then secreted. Only polymeric forms of $\operatorname{IgA}$ have high affinity for and thus can bind to $\mathrm{pIgR}$. A tyrosine residue in the IgA molecule plays an important role in the binding of $\operatorname{IgA}$ to $\mathrm{pIgR}$, since binding and transcytosis of $\operatorname{IgA}$ often are decreased after iodination of the IgA (Schiff et al., 1986). The J chain is required for the binding of $\operatorname{IgA}$ to $\mathrm{pIgR}$ and subsequent intracellular transport of IgA (Brandtzaeg and Prydz, 1984), although pIgR does not interact directly with the $\mathrm{J}$ chain. The first homologous domain at the $\mathrm{NH}_{2}$-terminal of $\mathrm{pIgR}$ 


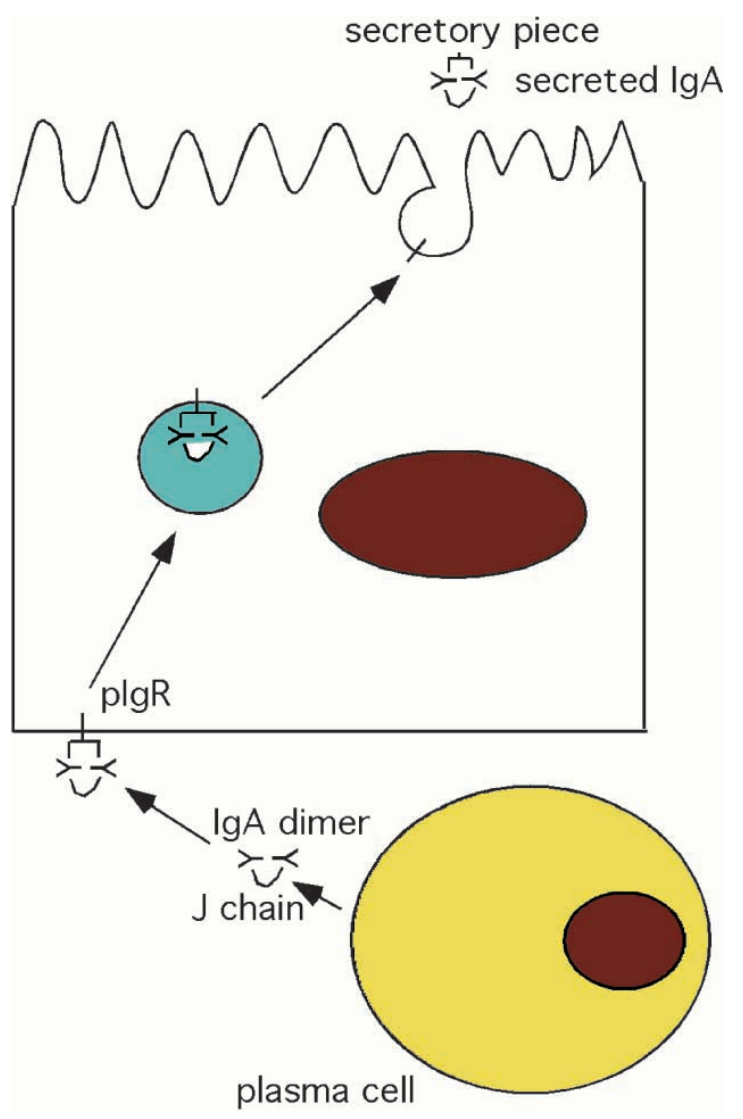

FIGURE 2 Schematic representation of the transcellular pathway for IgA secretion. Dimeric IgA secreted by plasma cells binds to pIgR, which is located on the basolateral membrane of BEC. The IgA-pIgR complex is internalized and transported across BEC is the vesicle. Upon arriving the apical pole of $\mathrm{BEC}, \mathrm{pIgR}$ is proteolytically processed, which releases IgA coupled with secretory piece.

is necessary for binding IgA (Hanly et al., 1987) and at the BEC surface, IgA first interact with pIgR noncovalently (Lindh and Bjork, 1976). Later, the free sulfhydryl group on the IgA molecule initiates the so-called disulfide interchange reaction by reducing a disulfide bond on the pIgR. This reaction leads ultimately to the formation of two new inter-molecular disulfide bonds between the $\operatorname{IgA}$ molecule and pIgR (Pardo et al., 1979). Interestingly, even though some degree of cross-affinity between $\operatorname{IgA}$ and $\mathrm{pIgR}$ of different species exists, the ability of IgA from one species to bond covalently to $\mathrm{pIgR}$ of different species is quite variable suggesting that the reaction requires certain conformational characteristics of both the $\operatorname{IgA}$ and the pIgR (Socken and Underdown, 1978).

TABLE I Predominant cellular location of pIgR in hepatobiliary tissues in various animal species

\begin{tabular}{lc}
\hline Species & Location of pIgR \\
\hline Rat & Hepatocytes \\
Rabbit & Hepatocytes \\
Mouse & Hepatocytes \\
Human & BEC \\
Monkey & Unknown (not on hepatocytes) \\
Guinea pig & BEC \\
\hline
\end{tabular}

After binding, the $\operatorname{IgA}-\mathrm{pIgR}$ complexes are internalized into coated endocytic vesicles which are routed across the epithelial cells (transcytosis) to the apical pole. Transport of the formed complexes is size dependent as pentameric IgM and large $\operatorname{IgA}$ immune complexes are generally transported less efficiently into bile than dimeric IgA (Socken et al., 1981). For example, complexes of trinitrophenylated bovine thyroglobulin (molecular weight of approximately $970 \mathrm{kDa}$ ) and polymeric $\operatorname{IgA}$ were transported less well than IgAtrinitrophenylated human albumin complexes (molecular weight of approximately $460 \mathrm{kDa}$ ). Soon after endocytosis, the $\operatorname{IgA}-\mathrm{pIgR}$ complexes are localized in a vesicular-tubular network, where the sorting of $\operatorname{IgA}-$ pIgR complexes from other endocytosed ligands presumably occurs. The vesicles containing $\operatorname{IgA}-\mathrm{pIgR}$ complexes, smooth-coated and vary in size from 100 to $160 \mathrm{~nm}$ in diameter, then are transported across the cell, avoiding interaction with lysosomes and Golgi complexes, and fuse with the bile canalicular membrane (Hoppe et al., 1985). This process also depends on functioning microtubules since treatment with colchicine abolishes the transport of IgA (Mullock et al., 1980) The transcellular migration also appears to involve only discrete vesicles, as there was no extensive connection between structures in the sinusoidal and bile canalicular regions (Hoppe et al., 1985).

The final step of the IgA delivery pathway involves the proteolytic cleavage of the IgA-pIgR complexes at the bile canalicular pole of the hepatocytes (or apical pole of the $\mathrm{BEC}$ ). At this step, $\mathrm{pIgR}$ is proteolytically processed to yield two proteins: a soluble fragment of pIgR called secretory piece (SC) and a transmembrane anchoring fragment containing the cytoplasmic tail of $\mathrm{pIgR}$, which remains on the vesicular membrane. The SC is released into the bile alone with $\operatorname{Ig} \mathrm{A}$, where it acts to protect the $\operatorname{Ig} \mathrm{A}$ from degradation thereby increasing the half-life of $\operatorname{Ig} \mathrm{A}$ in the bile. The exact mechanism and location of this proteolytic cleavage remain incompletely understood. Immunohistochemical studies have shown an accumulation of $\operatorname{IgA}$ and $\mathrm{pIgR}$ at or near the bile canalicular membrane before exocytosis of IgA (Takahashi et al., 1982), suggesting that the fusion of the endocytic vesicle with the bile canalicular membrane or the proteolysis of pIgR is the rate-limiting step in the pathway. By using the monoclonal antibodies specific for the cytoplasmic tail of $\mathrm{pIgR}$, it has been shown that either the cytoplasmic tail itself or other slightly degraded fragments are also released into the bile, as opposed to being degraded intracellularly (Solari et al., 1986). Interestingly, the SC is proteolytically processed for a second time by a metalloprotease present on the brush border plasma membrane of the jejunum into a smaller form (Ahnen et al., 1986).

The role and, therefore, the biological significance of the transport of IgA from the plasma into the bile have not been clearly defined. However, there are at least three proposed functions (Fig. 3). First, IgA in bile provides protection for the biliary tree and liver against invading pathogens by 


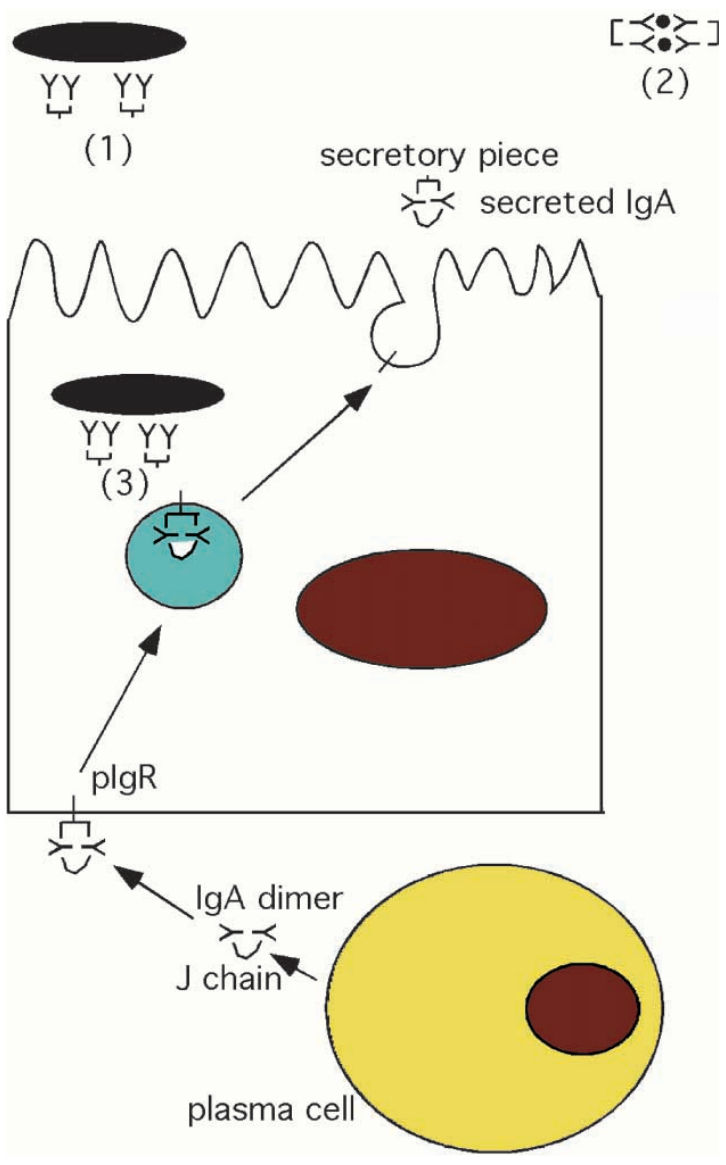

FIGURE 3 Proposed function of antibody in the bile. (1) Binding to extracellular pathogen and preventing its attachment to the BEC. (2) Binding to free antigen, forming immune complex, and facilitating its excretion. (3) Binding to intracellular pathogen during its transcytosis.

preventing the attachment of microorganisms and/or their toxins. Natural IgA antibodies to various intestinal bacteria are present in bile and inoculation into the intestinal lumen or intestinal lymphoid tissues of various antigens resulted in specific IgA antibodies in bile and protected experimental animals from, for example, cholangitis (Aagaard et al., 1996). Second, potential harmful antigens present in the circulation can be cleared into bile in the form of immune complexes with $\operatorname{Ig} \mathrm{A}$, thereby reducing the possibility of a systemic reaction. Indeed, transport of intravenously injected free antigen into bile by circulating $\operatorname{IgA}$, either passively administered or actively induced, has been demonstrated in rats. This could be especially important since a state of chronic inflammation might constantly arise given that the gastrointestinal tract is in contact with enormous diversity and amount of antigens daily (Harmatz et al., 1982; Peppard et al., 1982). A third possible role for the transport of IgA from plasma into bile is to provide specific protection against invading microorganisms as during the transcytosis process, the IgA antibodies can encounter and bind to an intracellular microbial pathogen. For example, co-localization of viral envelope proteins of Sendai and influenza viruses and IgA monoclonal antibodies specific to that viral protein has been demonstrated by 2-color immunofluorescence in a recent study (Mazanec et al., 1995).

Different animal species have different capacities to transfer IgA from plasma into bile as well as different location of $\mathrm{pIgR}$ within the liver. Other factors may also influence the $\operatorname{IgA}$ transport and pIgR expression. For example, the synthesis and expression of pIgR appears to be regulated during cellular differentiation and development. In the rat, immunorecognizable $\mathrm{pIgR}$ appears in intestinal epithelial cells between 10 and 15 days after birth, corresponding to the appearance in the lamina propria of IgA-producing plasma cells (Nagura et al., 1978). pIgR then reaches adult levels of expression by 40 days after birth. In rats, the hepatobiliary secretion of $\operatorname{IgA}$ decreases with age, as a direct result of an age-related decrease in the number of pIgR present on hepatocytes (Daniels et al., 1985). In contrast, in humans, pIgR has a different time course and is observed in fetal tissues prior to the appearance of either IgA or IgA-producing plasma cells (Ogra et al., 1972).

The regulation of the expression of $\mathrm{pIgR}$, and consequently the transport of $\mathrm{IgA}$ into external secretions may be tissue-specific as well as dependent on specific hormones and other chemical influences. The amount of pIgR synthesized by uterine or lacrimal cells may be influenced by sex steroids (Sullivan and Wira, 1981; Sullivan et al., 1984) as pIgR concentration in the tears of male rats is approximately 5-fold greater than that in a female. Castration results in a decrease of $\mathrm{pIgR}$ concentration in the tears. In hepatocytes, regulation of pIgR synthesis by glucocorticoids was also noted (Wira and Colby, 1985) as pIgR increased significantly after the addition of cortisol to the culture medium. Furthermore, this effect was abolished when either estradiol or cyclohexamide was added to the medium, which indicates that expression of $\mathrm{pIgR}$ is controlled both transcriptionally and translationally. Additionally, the synthesis and secretion of pIgR by HT-29 cells, a human colonic carcinoma cell line, can be increased by treatment with $\gamma$-interferon $(\gamma$-IFN) (Sollid et al., 1987), tumor necrosis factor (TNF)- $\alpha$ (Kvale et al., 1988), or by growing the cells in glucose-free, galactose-substituted medium (Rao et al., 1987).

The transport of $\operatorname{IgA}$ into bile is related to bile flow. Transient bile duct ligation $(2 \mathrm{~h})$ dramatically decreased liver transport of $\operatorname{IgA}$ in the period subsequent to ligation (Kloppel et al., 1987). The amount of IgA secreted into the bile was decreased to one-tenth of control value before ligation. In the rat, treatment with $17 \alpha$-ethnylestradiol $(5 \mathrm{mg} / \mathrm{kg}$ for 5 days) reduced bile flow by greater than $60 \%$. In parallel, the transport of intact IgA into bile decreased by $43 \%$ (Goldsmith et al., 1987). Table II summarizes the regulation of $\mathrm{pIgR}$ expression and/or $\operatorname{IgA}$ transport by various agents.

In addition to $\operatorname{IgA}$, other subclasses of immunoglobulins are also present in the bile. The concentration of biliary $\mathrm{IgG}$ is less than $8 \%$ the concentration of serum $\mathrm{IgG}$ (Manning et al., 1984). It appears that bile IgG mainly 
TABLE II Regulation of $\mathrm{pIgR}$ expression/IgA transport by various agents

Effect on pIgR expression/IgA transport

\begin{tabular}{cc}
\hline Increase & Decrease \\
\hline Androgen & Aging \\
Cortisol & Bile duct ligation \\
IFN- $\gamma$ & $17 \alpha$-ethnylestradiol \\
TNF- $\alpha$ & \\
\hline
\end{tabular}

originates from diffusion from blood. However, this mechanism was not supported in one study on human bile after tetanus toxoid immunization. The kinetics of the biliary $\operatorname{IgG}$ response in this study differed significantly from that found in serum. Moreover, when compared with paired sera response, the peak response in the bile exceeded that of the sera and showed 19-fold more abundant $\operatorname{IgG}$ and 45 -fold more abundant $\operatorname{Ig} \mathrm{A}$ than could have arrived by diffusion. This suggests that intrahepatic antibody production for export to the intestinal tract may occur in humans (Hansen et al., 1989). Similar to the origins of $\operatorname{IgG}$, trace amounts of IgM in bile may be either the result of leakage from blood or the presence of local IgM-producing plasma cells within the liver. The latter is supported by another study which showed that antigen entering the bloodstream stimulated a population of cells in the spleen to migrate to the liver. These cells then produce and secrete IgM into bile, thereby providing rapid and localized immunological response to invading microorganisms (Jackson and Walker, 1983).

\section{IMMUNE RESPONSE ROLE-SYNTHESIS OF CHEMOKINES, CYTOKINES, AND OTHER MEDIATORS}

The ability of BEC to express and secrete chemokines and cytokines is crucial for biliary innate immune defenses since these cells are the initial contact points for potential pathogenic microorganisms in the bile or ascending from the intestinal tract via the biliary tree. Locally secreted chemokines and cytokines are important signals for recruitment of other immune cells. Human BEC express and secrete IL-8 and monocyte chemotactic protein-1 (MCP-1) promoting the recruitment of neutrophils and monocytes or T-lymphocytes, respectively, to the portal tracts. When stimulated with proinflammatory cytokines such as interleukin (IL)- 1 or TNF- $\alpha$, this response is rapidly upregulated. When BEC were cocultured in transwell chamber below monolayers of endothelial cells, the transendothelial migration of neutrophils was observed. This response was blocked by antibodies to CD18 or CD11 but only partially inhibited by antibodies to IL-8 (Morland et al., 1997). IFN- $\gamma$ had a differential effect since it reduced IL- 8 but enhances MCP-1 secretion. The recruited neutrophils, monocytes, or T-lymphocytes can act as part of a protective response against ascending biliary infections or as participants in the pathological inflammation of the bile ducts like in PBC.

Studies of BEC in culture have shown that IL-6 synthesis and secretion into the medium. The TNF receptor and to a lesser extent IL- 6 receptor $\alpha$ chain are also present in BEC. Damaged BEC also have an increased expression of both IL-6 mRNA and TNF- $\alpha$ mRNA compared to normal liver suggesting an possible autocrine effect (Yasoshima et al., 1998). The secreted IL-6 and TNF- $\alpha$ could act in a paracrine or autocrine fashion as IL-6 increases BEC DNA labeling index from 4- to 6-fold after $24 \mathrm{~h}$ in primary cultures maintained in serum-free conditions and promotes BEC proliferation in vitro (Matsumoto et al., 1994). Second, these cytokines have an effect on lymphocytes in the vicinity of portal tracts. For example, IL-6 may promote terminal differentiation of $\mathrm{B}$ cells and stimulate secretion of immunoglobulins. TNF- $\alpha$ may induce expression of various adhesion molecules on BEC (Ayres et al., 1993) as well as the cytotoxic activities of $\mathrm{T}$ lymphocytes. Finally, IL-6 and TNF- $\alpha$ may mediate direct tissue damage by means of inflammation and apoptosis as treatment with TNF- $\alpha$ induced apoptosis in cultured rat hepatocytes (Bour et al., 1996).

BEC also synthesize and secrete other peptides and mediators, such as transforming growth factor (TGF)- $\beta_{2}$ (Milani et al., 1991), endothelin-1 (Caligiuri et al., 1998), platelet-derived growth factor (PDGF)-B chain (Milani et al., 1991), and nitric oxide (NO) (Vos et al., 1997). BEC do not produce these mediators under normal physiological conditions, but actively synthesize them in many conditions of acute and chronic liver injury. Thus, activated BEC communicate extensively with other immunological cells, including lymphocytes, neutrophils, fibroblasts, and Kupffer cells (macrophages).

\section{IMMUNE RESPONSE ROLE-EXPRESSION OF ADHESION MOLECULES}

BEC could intensify and localize the immune response by expressing selected cell surface adhesion molecules. Both in vivo and in vitro $\mathrm{BEC}$ from both diseased and normal livers express intercellular adhesion molecules (ICAM)-1, leukocyte function antigen (LFA) -3, major histocompatibility complexes (MHC)-I, and to a lesser degree, MHC-II constitutively in primary cultures (Ayres et al., 1993; Cruickshank et al., 1998) (Fig. 4). When treated with proinflammatory cytokines such as TNF- $\alpha$, IFN- $\gamma$, or IL-1, a significant increase of ICAM-1, MHC-I, and MHC-II expression was noted from both the diseased and normal liver (Ayres et al., 1993). In another study using BEC cell lines (PLC/PRF/5, HepG2, Hep3B, and CC-SW), all expressed MHC-I, LFA-3, ICAM-1, and EGF receptor. Furthermore, all but Hep3B expressed CD95. Similarly, proinflammatory cytokines such as IFN- $\gamma$ and TNF- $\alpha$ upregulated surface expression of ICAM-1, MHC-1, and MHC-II. IL-4, a Th2 cytokine, also upregulated CD95 


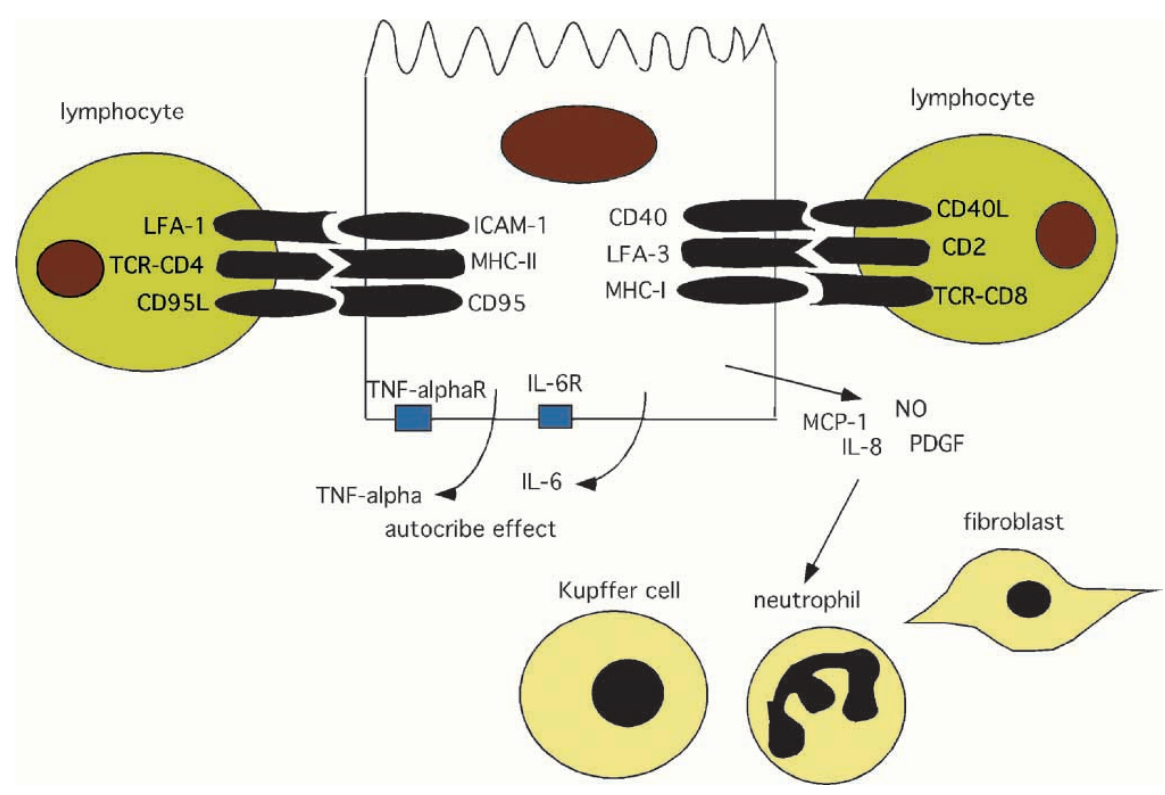

FIGURE 4 BEC constitutively express certain adhesion molecules, including ICAM-1, LFA-3, and CD40, which interact with surrounding lymphocytes expression LFA-1, CD2, and CD40L. BEC also express MHC-I and MHC-II, making them cytotoxic targets and/or becoming professional APC. Cytokines produced by BEC have either autocrine or paracrine effects, which can modulate the functions of other immunological cells in the vicinity.

expression while TGF- $\beta$, an anti-inflammatory cytokine, markedly downregulated cell surface expression of CD95, but increased expression of LFA-3 (Cruickshank et al., 1998). The effect of proinflammatory cytokines on the expression of adhesion molecules and MHC-I is consistent with the hypothesis that BEC are not innocent bystanders during inflammatory responses but active participants in the inflammatory reactions observed in liver immunemediated disorders (Table III).

As BEC express MHC-I and LFA-3, important adhesion molecules for lymphocyte trafficking and recognition, they can also act as targets for cytolytic $\mathrm{T}$ cells. It has been demonstrated that allogeneic lymphocytes could bind to human primary BEC cultures and this interaction was enhanced by activation of either participating cell types. At least $50 \%$ of the overall interaction is dependent on LFA-1 on cytotoxic T-lymphocytes, which is the ligand for ICAM-1 expressed on BEC. BEC are also susceptible to lysis by cytokine-activated natural killer (NK) cells (Leon et al., 1997). In the presence of antigen in association with MHC molecules, the lymphocytes would become activated to recognize $\mathrm{BEC}$ as a potential target and

TABLE III Effect of cytokines on the expression of membrane surface markers in BEC

\begin{tabular}{lcccccc}
\hline & ICAM-1 & MHC-I & MHC-II & LFA-3 & CD95 & CD40 \\
\hline Unstimulated & + & + & \pm & + & + & + \\
TNF- $\alpha$ & $\uparrow$ & $\uparrow$ & $\uparrow$ & No effect & NA & $\uparrow$ \\
IFN- $\gamma$ & $\uparrow$ & $\uparrow$ & $\uparrow$ & No effect & NA & $\uparrow$ \\
IL-1 & $\uparrow$ & $\uparrow$ & $\uparrow$ & NA & NA & NA \\
TGF- $\beta$ & $\downarrow$ & $\downarrow$ & $\downarrow$ & $\uparrow$ & $\downarrow$ & No effect \\
IL-4 & NA & NA & NA & NA & $\uparrow$ & NA \\
\hline
\end{tabular}

NA, not available. expression of adhesion molecules would then render them susceptible to cytolytic mechanisms by attracting cytotoxic T lymphocytes (CTL). It is also possible that upregulated expression of MHC-I on BEC increases the avidity of the $\mathrm{T}$ cell receptor (TCR)/MHC interaction, which in turn increases their potential as target cells for $\mathrm{T}$ cell-mediated attack. The fact that LFA-3 is constitutively expressed on BEC suggests an interaction with CD2 on CTL and/or NK cells that may lead to cytotoxicity (Leon et al., 1997). It has also been found that TCR stimulation or treatment with phorbol ester rapidly increased the avidity of CD2 for LFA3 in murine T cell hybridomas transfected with human CD2 (Hahn et al., 1993). Cell lines expressing single amino acid mutations of the carboxyl terminal asparagines of CD2 lost CD2 avidity regulation through TCR activation. This regulation requires both protein tyrosine kinases and protein kinase $\mathrm{C}$. Agents that increase intracellular cAMP levels also upregulated CD2 avidity. In conclusion, the CD2/LFA-3 interaction not only acts as the physical bridge between T lymphocytes and BEC but also are affected by or turn on other signal transduction pathways

Viral infection can also modulate BEC expression of adhesion molecules. For example, cytomegalovirus (CMV) infection increased BEC surface expression of MHC-I but not MHC-II (Scholz et al., 1997). This augmentation of MHC-I expression was observed when the virally infected BEC was cocultured with autologous but not allogeneic peripheral blood lymphocytes. CMV also reduced the IFN- $\gamma$ mediated induction of MHC-II while MHC-I was unchanged. This also suggests that a viral infection can modulate the immunogenic potential of BEC by making them more susceptible to T lymphocyte attack due to increased MHC-I expression. 
An earlier study has confirmed the constitutive expression of MHC-II from primary BEC cultures of both normal and diseased livers (Cruickshank et al., 1998) and that proinflammatory cytokines such as TNF- $\alpha$, IFN$\gamma$, or IL-1 upregulated the MHC-II expression of BEC. The reason for this expression of MHC-II on BEC remains unclear although this has lead to suggestions that BEC might act as professional antigen presenting cells (APC) as APC are characterized by MHC-II expression. For example, it has been shown that the increased destruction of bile duct epithelium is associated with MHC-II-specific lymphocytes. In vivo studies have also shown that intraperitoneal administration of IL-2 in mice induces not only luminal expression of MHC-II on BEC, but also lymphocyte infiltration around bile ducts in liver (Himeno et al., 1992). Most infiltrating lymphocytes were $\mathrm{T}$ cells and about one-third of them were positive for IFN$\gamma$ suggesting that the infiltration of lymphocytes is dependent on endogenous IFN- $\gamma$ production. However it is well accepted that the expression of MHC-II alone is not sufficient for antigen presentation to naïve $\mathrm{T}$ lymphocytes as successful primary activation and subsequent proliferation of $\mathrm{T}$ cells by APC requires costimulatory signals, B7-1 (CD80) and B7-2 (CD86). However, neither CD80 nor CD86 are constitutively expressed by unstimulated human BEC and high concentrations of either IFN- $\gamma$, $\mathrm{TNF}-\alpha$, or both in combination failed to induce their expression on BEC (Leon et al., 1997). While this argues that BEC are unlikely to act as professional APC, it is still possible that BEC may present antigens in an inefficient manner which may result in specific $\mathrm{T}$ cell anergy or deletion. The anergic $\mathrm{T}$ cells may function as suppressor cells, inhibiting subsequent $\mathrm{T}$ cell activation even in the presence of professional APC.

\section{References}

Aagaard, B.D., Heyworth, M.F., Oesterle, A.L., et al. (1996) "Intestinal immunisation with Escherichia coli protects rats against Escherichia coli induced cholangitis", Gut 39, 136-140.

Ahnen, D.J., Singleton, J.R., Hoops, T.C. and Kloppel, T.M. (1986) "Posttranslational processing of secretory component in the rat jejunum by a brush border metalloprotease", J. Clin. Investig. 77, $1841-1848$.

Alpini, G., Roberts, S., Kuntz, S.M., et al. (1996) "Morphological, molecular, and functional heterogeneity of cholangiocytes from normal rat liver", Gastroenterology 110, 1636-1643.

Alvaro, D. (1999) "Biliary epithelium: a new chapter in cell biology", Ital. J. Gastroenterol. Hepatol. 31, 78-83.

Alvaro, D., Cho, W.K., Mennone, A. and Boyer, J.L. (1993) "Effect of secretion on intracellular $\mathrm{pH}$ regulation in isolated rat bile duct epithelial cells", J. Clin. Investig. 92, 1314-1325.

Alvaro, D., Gigliozzi, A., Fraioli, F., et al. (1997a) "Hormonal regulation of bicarbonate secretion in the biliary epithelium", Yale J. Biol. Med. 70, 417-426.

Alvaro, D., Mennone, A. and Boyer, J.L. (1997b) "Role of kinases and phosphatases in the regulation of fluid secretion and $\mathrm{Cl}^{-} / \mathrm{HCO}_{3}^{-}$ exchange in cholangiocytes", Am. J. Physiol. 273, G303-G313.

Alvaro, D., Alpini, G., Jezequel, A.M., et al. (1997c) "Role and mechanisms of action of acetylcholine in the regulation of rat cholangiocyte secretory functions", J. Clin. Investig. 100, $1349-1362$

Ayres, R.C., Neuberger, J.M., Shaw, J., et al. (1993) "Intercellular adhesion molecule-1 and MHC antigens on human intrahepatic bile duct cells: effect of pro-inflammatory cytokines", Gut 34, $1245-1249$.

Bour, E.S., Ward, L.K., Cornman, G.A. and Isom, H.C. (1996) "Tumor necrosis factor-alpha-induced apoptosis in hepatocytes in long-term culture", Am. J. Pathol. 148, 485-495.

Brandtzaeg, P. and Prydz, H. (1984) "Direct evidence for an integrated function of J. chain and secretory component in epithelial transport of immunoglobulins", Nature 311, 71-73.

Caligiuri, A., Glaser, S., Rodgers, R.E., et al. (1998) "Endothelin-1 inhibits secretin-stimulated ductal secretion by interacting with ETA receptors on large cholangiocytes", Am. J. Physiol. 275, G835-G846.

Cho, W.K., Mennone, A., Rydberg, S.A. and Boyer, J.L. (1997a) "Bombesin stimulates bicarbonate secretion from rat cholangiocytes: implications for neural regulation of bile secretion", Gastroenterology 113, 311-321.

Cho, W.K., Mennone, A. and Boyer, J.L. (1997b) "VIP stimulates bile secretion in cholangiocytes by cAMP-PKA independent mechanisms", Hepatology, 26.

Cruickshank, S.M., Southgate, J., Selby, P.J. and Trejdosiewicz, L.K. (1998) "Expression and cytokine regulation of immune recognition elements by normal human biliary epithelial and established liver cell lines in vitro", J. Hepatol. 29, 550-558.

Daniels, C.K. and Schmucker, D.L. (1987) "Secretory componentdependent binding of immunoglobulin $\mathrm{A}$ in the rat, monkey and human: a comparison of intestine and liver", Hepatology 7, 517-521.

Daniels, C.K., Schmucker, D.L. and Jones, A.L. (1985) "Age-dependent loss of dimeric immunoglobulin A receptors in the liver of the Fischer 344 rat", J. Immunol. 134, 3855-3858.

Delacroix, D.L., Courtoy, P.J., Rahier, J., et al. (1984) "Localization and serum concentration of secretory component during massive necrosis of human liver", Gastroenterology 86, 521-531.

Eisenmann-Tappe, I., Wizigmann, S. and Gebhardt, R. (1991) "Glutamate uptake in primary cultures of biliary epithelial cells from normal rat liver", Cell Biol. Toxicol. 7, 315-325.

Elsing, C., Kassner, A. and Stremmel, W. (1996) "Sodium, hydrogen antiporter activation by extracellular adenosine triphosphate in biliary epithelial cells", Gastroenterology 111, 1321-1332.

Fitz, J.G. (1997) "Evidence for paracrine regulation of biliary $\mathrm{Cl}^{-}$ secretion by purinergic signalling", In: Alvaro, D., Benedetti, A. and Strazzabosco, M., eds, Vanishing Bile Duct Syndrome-Pathophysiology (Kluwer Academic Publishers, London), pp 65-71.

Frizzel, R.A. and Morris, A.P. (1994) "Chloride conductance of saltsecreting epithelial cells", Current Topics in Membranes (Academic Press, New York) Vol. 42, pp 173-214.

Glaser, S.S., Rodgers, R.E., Phinizy, J.L., et al. (1997) "Gastrin inhibits secretin-induced ductal secretion by interaction with specific receptors on rat cholangiocytes", Am. J. Physiol. 273, G1061-G1070.

Goldsmith, M.A., Jones, A.L., Underdown, B.J. and Schiff, J.M. (1987) "Alterations in protein transport events in rat liver after estrogen treatment”, Am. J. Physiol. 253, G195-G200.

Hahn, W.C., Burakoff, S.J. and Bierer, B.E. (1993) "Signal transduction pathways involved in $\mathrm{T}$ cell receptor-induced regulation of $\mathrm{CD} 2$ avidity for CD58", J. Immunol. 150, 2607-2619.

Hanly, W.C., Cook, L., Kingzette, M., et al. (1987) "Rabbit secretory components: identification of a third allotype, t63", J. Immunol. 139, $1597-1601$

Hansen, P.G., Hennessy, E.J., Blake, H., et al. (1989) “Appearance of IgG and $\operatorname{IgA}$ antibodies in human bile after tetanus toxoid immunization", Clin. Exp. Immunol. 77, 215-220.

Harmatz, P.R., Kleinman, R.E., Bunnell, B.W., et al. (1982) "Hepatobiliary clearance of $\operatorname{IgA}$ immune complexes formed in the circulation", Hepatology 2, 328-333.

Himeno, H., Saibara, T., Onishi, S., et al. (1992) "Administration of interleukin-2 induces major histocompatibility complex class II expression on the biliary epithelial cells, possibly through endogenous interferon-gamma production", Hepatology 16, 409-417.

Hofmann, A.F., Z., Y.H., Schteingart, C.D., et al. (1997) "The cholehepatic circulation of organic anions: a decade of progress", In: Alvaro, D., Benedetti, A. and Strazzabosco, M., eds, Vanishing Bile Duct Syndrome-Pathophysiology (Kluwer Academic Publishers, London), pp 90-106.

Hoppe, C.A., Connolly, T.P. and Hubbard, A.L. (1985) "Transcellular transport of polymeric $\operatorname{IgA}$ in the rat hepatocyte: biochemical and morphological characterization of the transport pathway", J. Cell Biol. 101, 2113-2123. 
Jackson, G.D. and Walker, P.G. (1983) "The transient appearance of IgM antibodies in the bile of rats injected with Salmonella enteritidis", Immunol. Lett. 7, 41-45.

Kloppel, T.M., Hoops, T.C., Gaskin, D. and Le, M. (1987) "Uncoupling of the secretory pathways for $\operatorname{IgA}$ and secretory component by cholestasis", Am. J. Physiol. 253, G232-G240.

Kvale, D., Lovhaug, D., Sollid, L.M. and Brandtzaeg, P. (1988) “Tumor necrosis factor-alpha up-regulates expression of secretory component, the epithelial receptor for polymeric Ig", J. Immunol. 140, 3086-3089.

Lazaridis, K.N., Pham, L., Tietz, P., et al. (1997) "Rat cholangiocytes absorb bile acids at their apical domain via the ileal sodiumdependent bile acid transporter", J. Clin. Investig. 100, 2714-2721.

Lemaitre-Coelho, I., Jackson, G.D. and Vaerman, J.P. (1977) "Rat bile as a convenient source of secretory IgA and free secretory component", Eur. J. Immunol. 7, 588-590.

Leon, M.P., Bassendine, M.F., Gibbs, P., et al. (1997) "Immunogenicity of biliary epithelium: study of the adhesive interaction with lymphocytes", Gastroenterology 112, 968-977.

Lindh, E. and Bjork, I. (1976) "Binding of secretory component to dimers of immunoglobulin A in vitro. Mechanism of the covalent bond formation", Eur. J. Biochem. 62, 263-270.

Lira, M., Schteingart, C.D., Steinbach, J.H., et al. (1992) "Sugar absorption by the biliary ductular epithelium of the rat: evidence for two transport systems", Gastroenterology 102, 563-571.

Manning, R.J., Walker, P.G., Carter, L., et al. (1984) "Studies on the origins of biliary immunoglobulins in rats", Gastroenterology 87, 173-179.

Martinez-Anso, E., Castillo, J.E., Diez, J., et al. (1994) "Immunohistochemical detection of chloride/bicarbonate anion exchangers in human liver", Hepatology 19, 1400-1406.

Matsumoto, K., Fujii, H., Michalopoulos, G., et al. (1994) "Human biliary epithelial cells secrete and respond to cytokines and hepatocyte growth factors in vitro: interleukin-6, hepatocyte growth factor and epidermal growth factor promote DNA synthesis in vitro", Hepatology 20, 376-382.

Mazanec, M.B., Kaetzel, C.S., Lamm, M.E., et al. (1995) "Intracellular neutralization of Sendai and influenza viruses by IgA monoclonal antibodies", Adv. Exp. Med. Biol. 371A, 651-654.

Milani, S., Herbst, H., Schuppan, D., et al. (1991) "Transforming growth factors beta 1 and beta 2 are differentially expressed in fibrotic liver disease", Am. J. Pathol. 139, 1221-1229.

Morland, C.M., Fear, J., McNab, G., et al. (1997) "Promotion of leukocyte transendothelial cell migration by chemokines derived from human biliary epithelial cells in vitro", Proc. Assoc. Am. Physicians 109, 372-382.

Mullock, B.M., Jones, R.S., Peppard, J. and Hinton, R.H. (1980) "Effect of colchicine on the transfer of IgA across hepatocytes into bile in isolated perfused rat livers", FEBS Lett. 120, 278-282.

Nagura, H., Nakane, P.K. and Brown, W.R. (1978) "Breast milk IgA binds to jejunal epithelium in suckling rats", J. Immunol. 120, 1333-1339.

Nathanson, M.H. and Boyer, J.L. (1991) "Mechanisms and regulation of bile secretion", Hepatology 14, 551-566.

Ogra, S.S., Ogra, P.L., Lippes, J. and Tomasi, T.B., Jr. (1972) "Immunohistologic localization of immunoglobulins, secretory component, and lactoferrin in the developing human fetus", Proc. Soc. Exp. Biol. Med. 139, 570-574.

Pardo, A.G., Lamm, M.E., Plaut, A.G. and Frangione, B. (1979) "Secretory component is convalently bound to a single sub-unit in human secretory IgA", Mol. Immunol. 16, 477-482.

Peppard, J.V., Orlans, E., Andrew, E. and Payne, A.W. (1982) "Elimination into bile of circulating antigen by endogenous IgA antibody in rats", Immunology 45, 467-472.

Rao, C.K., Kaetzel, C.S. and Lamm, M.E. (1987) "Induction of secretory component synthesis in colonic epithelial cells", Adv. Exp. Med. Biol. 216B, $1071-1077$.
Schiff, J.M., Fisher, M.M., Jones, A.L. and Underdown, B.J. (1986) "Human $\operatorname{IgA}$ as a heterovalent ligand: switching from the asialoglycoprotein receptor to secretory component during transport across the rat hepatocyte", J. Cell Biol. 102, 920-931.

Scholz, M., Cinatl, J., Blaheta, R.A., et al. (1997) "Expression of human leukocyte antigens class I and class II on cultured biliary epithelial cells after cytomegalovirus infection", Tissue Antigens 49, 640-643.

Singh, S.K., Mennone, A. and Boyer, J.L. (1996) " $\mathrm{Na}^{+}-\mathrm{K}^{+}-2 \mathrm{Cl}^{-}$ cotransport participates in stimulated fluid secretion in isolated polarized bile duct units from rat liver", Hepatology 26(279A), (Abstract).

Socken, D.J. and Underdown, B.J. (1978) "Comparison of human, bovine and rabbit secretory component-immunoglobulin interactions", Immunochemistry 15, 499-506.

Socken, D.J., Simms, E.S., Nagy, B.R., et al. (1981) "Secretory component-dependent hepatic transport of IgA antibody-antigen complexes", J. Immunol. 127, 316-319.

Solari, R., Racine, L., Tallichet, C. and Kraehenbuhl, J.P. (1986) "Distribution and processing of the polymeric immunoglobulin receptor in the rat hepatocyte: morphological and biochemical characterization of subcellular fractions", J. Histochem. Cytochem. 34, 17-23.

Sollid, L.M., Kvale, D., Brandtzaeg, P., et al. (1987) "Interferon-gamma enhances expression of secretory component, the epithelial receptor for polymeric immunoglobulins", J. Immunol. 138, $4303-4306$.

Spirli, C., Granato, A., Zsembery, K., et al. (1998) "Functional polarity of $\mathrm{Na}^{+} / \mathrm{H}^{+}$and $\mathrm{Cl}^{-} / \mathrm{HCO}_{3}^{-}$exchangers in a rat cholangiocyte cell line", Am. J. Physiol. 275, G1236-G1245.

Strazzabosco, M. (1997) "New insights into cholangiocyte physiology", J. Hepatol. 27, 945-952.

Strazzabosco, M., Joplin, R., Zsembery, A., et al. (1997) "Na(+)dependent and -independent $\mathrm{Cl}^{-} / \mathrm{HCO}_{3}^{-}$exchange mediate cellular $\mathrm{HCO}_{3}^{-}$transport in cultured human intrahepatic bile duct cells", Hepatology 25, 976-985.

Strazzabosco, M., Spirli, C. and Okolicsanyi, L. (2000) "Pathophysiology of the intrahepatic biliary epithelium", J. Gastroenterol. Hepatol. 15, $244-253$.

Sullivan, D.A. and Wira, C.R. (1981) "Estradiol regulation of secretory component in the female reproductive tract", J. Steroid Biochem. 15, 439-444.

Sullivan, D.A., Bloch, K.J. and Allansmith, M.R. (1984) "Hormonal influence on the secretory immune system of the eye: androgen regulation of secretory component levels in rat tears", J. Immunol. 132, 1130-1135.

Takahashi, I., Nakane, P.K. and Brown, W.R. (1982) "Ultrastructural events in the translocation of polymeric IgA by rat hepatocytes", J. Immunol. 128, 1181-1187.

Tavoloni, N. (1987) "The intrahepatic biliary epithelium: an area of growing interest in hepatology", Semin. Liver Dis. 7, 280-292.

Tietz, P.S., Alpini, G., Pham, L.D. and Larusso, N.F. (1995) "Somatostatin inhibits secretin-induced ductal hypercholeresis and exocytosis by cholangiocytes", Am. J. Physiol. 269, G110-G118.

Vos, T.A., Gouw, A.S., Klok, P.A., et al. (1997) "Differential effects of nitric oxide synthase inhibitors on endotoxin-induced liver damage in rats", Gastroenterology 113, 1323-1333.

Wira, C.R. and Colby, E.M. (1985) "Regulation of secretory component by glucocorticoids in primary cultures of rat hepatocytes", J. Immunol. 134, 1744-1748.

Yasoshima, M., Kono, N., Sugawara, H., et al. (1998) "Increased expression of interleukin-6 and tumor necrosis factor-alpha in pathologic biliary epithelial cells: in situ and culture study", Lab. Investig. 78, 89-100. 


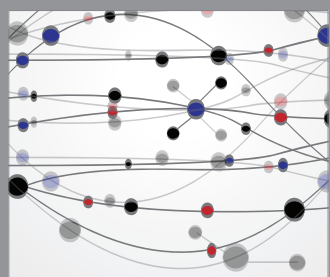

The Scientific World Journal
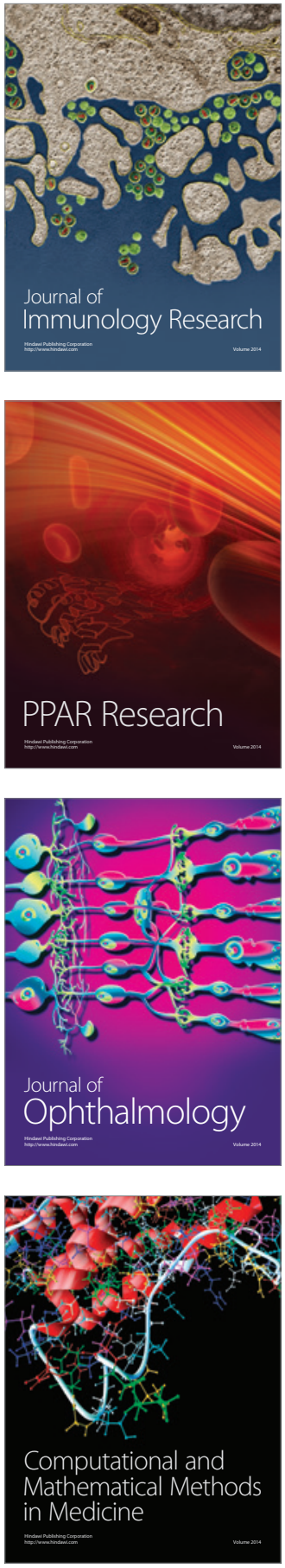

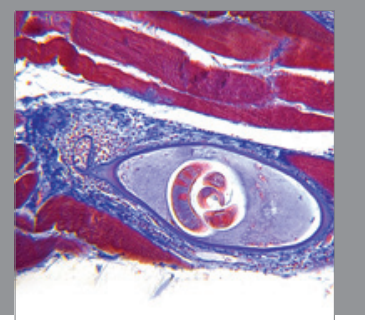

Gastroenterology

Research and Practice
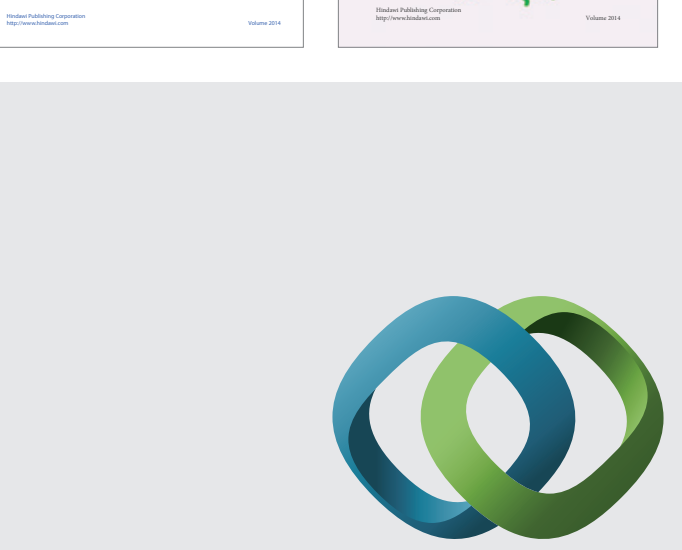

\section{Hindawi}

Submit your manuscripts at

http://www.hindawi.com
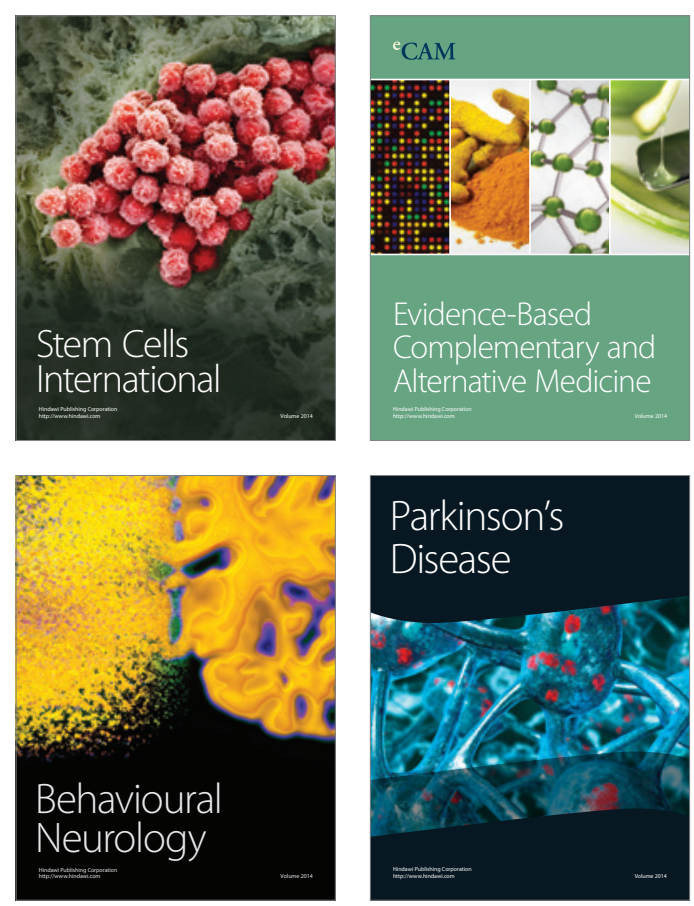

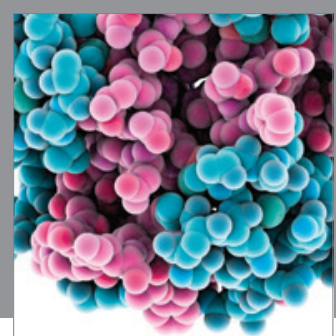

Journal of
Diabetes Research

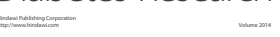

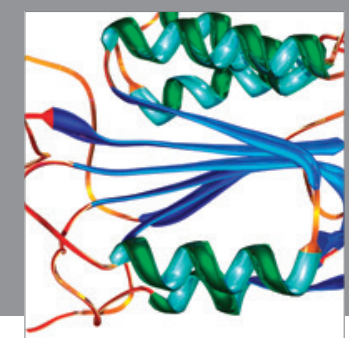

Disease Markers
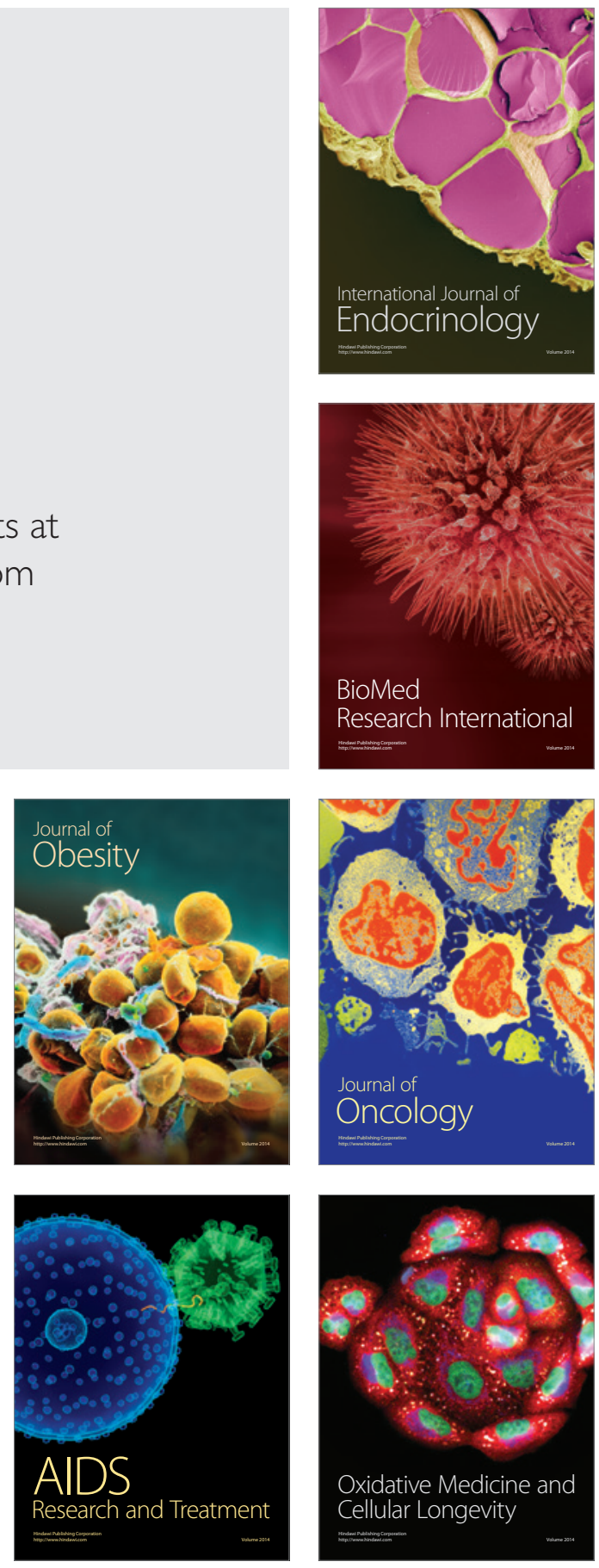